\title{
Editorial: Going from Good to Great
}

\author{
C. C. Chancey, Editor \\ American Journal of Undergraduate Research \\ University of Northern lowa \\ Cedar Falls, lowa 50614 USA
}

The current rapid pace of scientific development is stunning: biotechnology, robotics, nanoscience, bioinformatics, GIS, proteomics... Each of these new areas has moved from the research and graduate arenas into the undergraduate realm in the last decade. The technology that helps propel these advances often comes in versions that are relatively small and desktop ready, rather than simply large and room-filling.

This litany of opportunity even so is a long way from most undergraduate teaching laboratories. Money and the necessary faculty development are usually very hard won achievements-and I speak as one in the United States, realizing the even greater difficulties of science colleagues in other parts of the world. But, pace my distant colleagues, allow me to speak to my US colleagues:

Science has never been so ascendant in our country and the concomitant technology never more an assumed part of our everyday lives. Why then are we-university scientists and teachers-working so hard, and increasingly harder, to attract good students to our areas? The "business of America is business" said Calvin Coolidge, a sense of purpose that may appear to be the default assumed by many of our undergraduates. But accountancy, philosophy or English literature cannot, I think, be blameworthy for the relative malaise of student engagement in the natural sciences. It is our very success, our mighty edifice of intellectual achievement, that leaves many capable students wondering what places they could possibly have in such an awesome enterprise. Ambition and a willingness to work hard are as necessary in English lit and business as in any science course, but English lit and business possess a clearly human scale that science often doesn't.

How should our science programs and their majors' courses respond? Not by teaching the "great scientists of history" (engaging though that is) but by incorporating community engagement. Some science programs have senior projects or capstone programs that pull their students into the wider world. Why not start this process in the first year, as a set part of the course? Maybe it is as little as two or four hours the first semester, but the importance is in the attempt-always clear to students. In my area (physics), I can imagine first-year students doing an energy audit of buildings, or a traffic survey, or going into local schools to make presentations. An effort that puts science students into the community, even for short periods, will be a real step toward making science more human-scale-something that we as professionals have always known.

Taking our science programs from "good" to "great" is more than a matter of subject rigor and currency; it must be a matter of relevance to students and their families. We can rightly say that science leads our technological world, but this fact clearly does not provide sufficient inspiration for many science-capable students.

Are you teaching a major's course? Do you rush to cover the necessary material? Introduce a project, some application that gets your students out of the classroom for a few hours. Content and rigor likely won't suffer in any way that increased student interest and engagement won't pay back. I'm teaching a major's course right now (Experiment Design) and I'm looking for a project. 


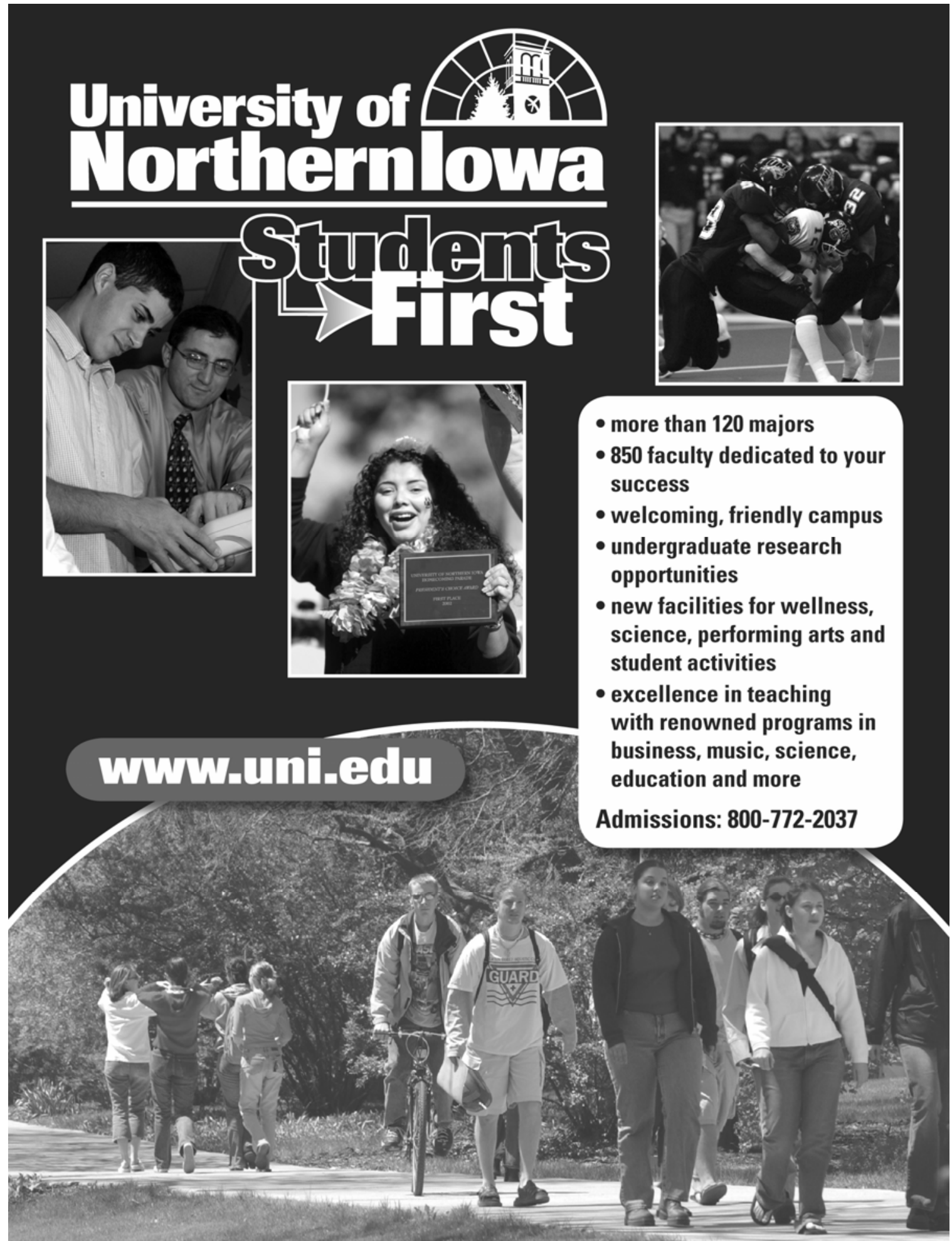

